\title{
Wood-Based Epoxy Resin's Synthesis Using Decayed Woody Material from Mushroom Cultivation
}

\author{
Sayuri Kawamura, Qingyue Wang* \\ Graduate School of Science and Engineering, Saitama University, Saitama-shi 338-8570, Japan
}

Corresponding Author Email: seiyo@mail.saitama-u.ac.jp

https://doi.org/10.18280/ijdne.150203

Received: 4 January 2020

Accepted: 17 March 2020

\section{Keywords:}

liquefaction, decayed woody samples, epoxy resin

\begin{abstract}
The aim of this study is to investigate the epoxy resin prepared from liquefied decayed woody materials after mushroom cultivation, in order to widen the applicable range of liquefaction technology. Liquefaction technology is valid replacement of fossil fuel and serving the Sustainable Development Goals. Decayed materials have less usage due to the damage to its original form and the deterioration of its strength. However, decay refers to decomposition of woody composition of cellulose, hemicellulose and lignin, which are easy to be liquefied. Decayed wood woody material was first liquefied by reaction with polyethylene glycol and glycerin. Then epoxy function groups were introduced to the liquefied wood by the glycidyl etherification. The synthesized epoxy resins from decayed woody sample have the similar chemical and technological properties with these from control woody samples. This reality indicates that decayed woody materials have potentially to be used for a wide range of applications including binding and contribute to construct sustainable development society.
\end{abstract}

\section{INTRODUCTION}

Sustainable Development Goals (SDGs) was brought up in United Nations Sustainable Development Summit 2015. About $24 \%$ of SDGs content is directly linked with the environmental issues. Environment is considered as the foundation of life, and almost $70 \%$ of SDGs content relates to environmental issues. Solving the environmental problem plays a key role in sustainable development as well as to fulfill the SDGs goal. However, fossil fuel is still used in energy and material area because it is a non-renewable source of energy. The human life is surrounded by numerous plastic products produced using petroleum. We cannot even think a single day without using any plastic products. To solve these problems, natural and renewable resources are gaining popularity as a potential energy source to replace petroleum for preparing biobased materials.

Among various ways of using biomass, liquefaction treatment is an effective and promising method to convert solid biomass into liquid polymer or aromatics that can be directly used to produce value-added polymers. The liquefaction of wood in the presence of phenols and alcohols have been intensively studied by $\mathrm{Pu}$ and Shiraishi [1]. The liquefied wood has a high reactivity due to the large number of phenolic-OH groups and alcoholic-OH groups. The liquefaction process is one of the technologies for producing resin precursor through etherification or esterification of $\mathrm{O}-\mathrm{H}$ single bond of the major component of material. Several types of resin products can be synthesized by reacting the functional groups of biomass and organic solvent.

Recent researchers are more concentrated on exploring the mechanism [2] and wide range application of liquefaction in various fields. Many kinds of woods, chemically modified woods, wood wastes, and some nonwoods have been successfully. For example, wood [3], starch [4] were extensively used for liquefaction to synthesis polyurethane foam (PUF). Nowadays, more and more researchers' theme moves the focus to epoxy resin, which is prepared from lignin due to the growing demand. The epoxy resin has good mechanical and adhesive performances, and is widely used in various fields, such as adhesives, coatings and matrix resins of composites. Lignin has a highly branched structure consisting of phenyl propane units. The content of phenolic hydroxyls in the lignin macromolecules allows the utilization of lignin as a substitute for phenol in the synthesis of an epoxy resin. The introduction of the aromatic structure in lignin into the epoxy resin can enhance the adhesive strength and improve the thermal properties. The reason is that large number of the phenolic hydroxyls in the lignin molecules are etherified. Liquefaction can release some of the etherified hydroxyl groups and reduce the molecular weight of lignin. The release of hydroxyl groups can increase the number of reactive groups. The reactivity of lignin can thus be improved. Several approaches have been taken to incorporate lignin or lignin derivatives into epoxy resins $[5,6]$.

However, few researchers have used decayed wood to produce epoxy resin to find out an alternate and sustainable way to make good use of decayed wood. We studied the woody samples decayed by white-rot fungus and liquefied successfully [7]. Subsequently, the liquefaction of the woody material from mushroom cultivation was successful [8]. The purpose of this study is to analyze the liquefied woody material from mushroom cultivation and the epoxy resin produced from that. 


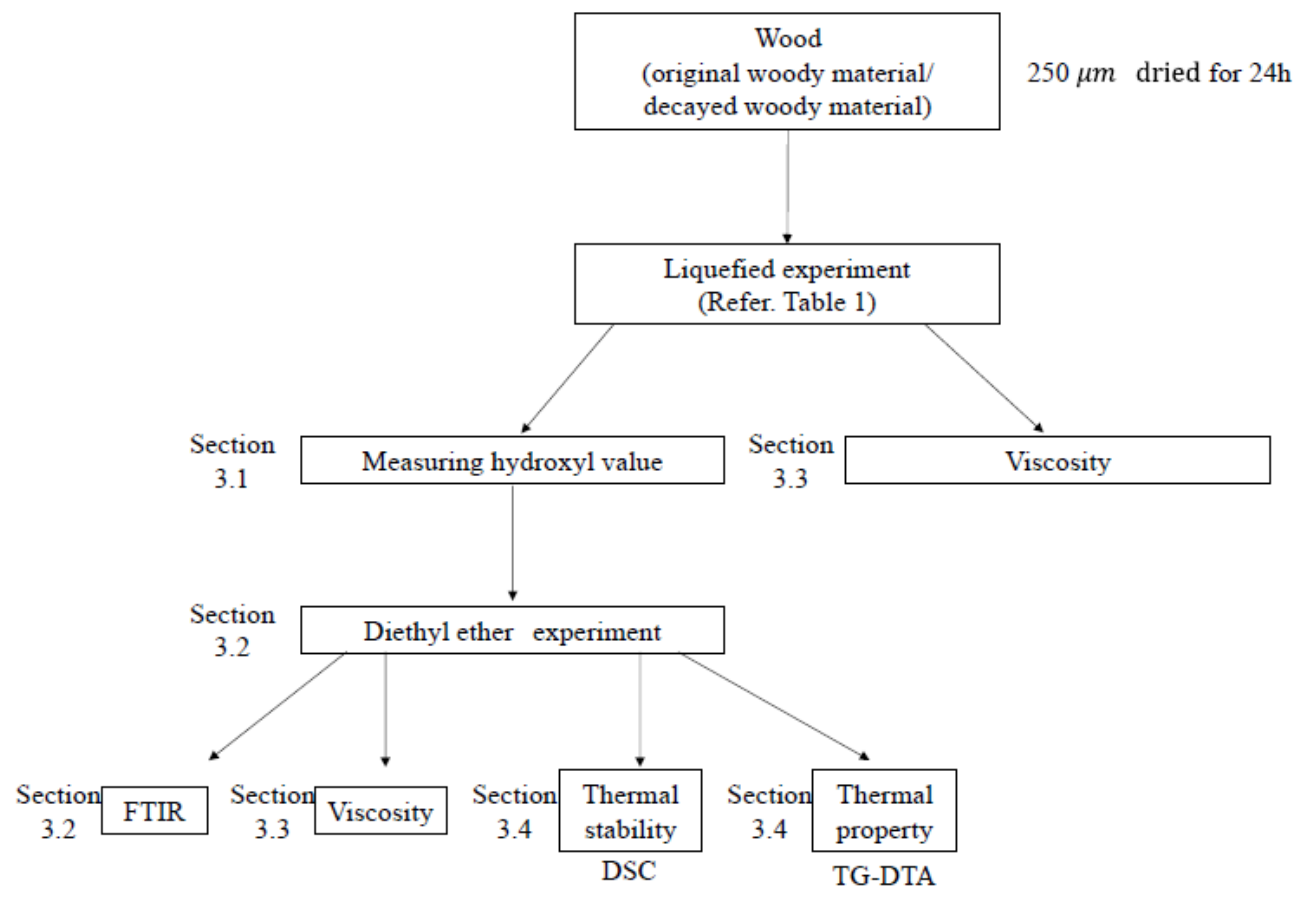

Figure 1. An outline of experimental procedure

\section{MATERIALS AND METHODS}

\subsection{Materials}

Polyethylene glycol, epichlorohydrine, and all other chemicals for liquefaction of wood and synthesis of woodbased epoxy resins were of reagent grade and were used without further purification.

\subsection{Liquefied experiment}

The total of 2 samples was collected and analyzed for chemical characteristics as shown in Figure 1. Liquefaction experiment was carried out according to Wang et al. [8]. The reaction condition is following them [8]. The temperature is chosen the highest one because there is the biggest difference of residue between original woody material and decayed woody material. In other words, the wood was liquefied with solvent mixture (polyethylene glycol 400: glycerin $=9: 1 /$ weight rate) at $140^{\circ} \mathrm{C}$. The solvent/ wood ratio was $6 / 1$ (Table 1).

Table 1. Reaction condition of liquefaction experiment

\begin{tabular}{cc}
\hline Solvent & polyethylene glycol: glycerin=9:1/weight rate \\
\hline Catalyst & Sulfuric acid \\
\hline Ratio & Wood: Solvent: Catalyst=6: $1: 0.01 /$ weight rate \\
\hline Time & $300 \mathrm{~min}$ \\
\hline Temperature & $140^{\circ} \mathrm{C}$ \\
\hline
\end{tabular}

After a defined duration, the reactor was cooled to room temperature rapidly to avoid over-reaction. In order to remove the insoluble residue in the liquefaction process, the black liquid after the liquefied treatment was filtered with methanol using a filter paper (JIS P 3801: $1 \mu \mathrm{m}$ particle-retainable) and methanol was evaporated (NA-2SGS, AS ONE).

\subsection{Measuring hydroxyl value}

In our study, acidity and hydroxyl values of liquefied wood was measured adapted from Ertaş et al. [9]. The hydroxyl value is calculated with acid values. The hydroxyl and acid value of liquefaction wood were determined by titration. Blank titration was conducted using the same procedure.

The hydroxyl value of the liquefied wood is defined as the amount (milligrams) of potassium hydroxide equivalent to the acetic anhydride consumed in the sodium hydroxide of $1.0 \mathrm{~g}$ of liquefied wood. A mixture of $8.0 \mathrm{~g}$ liquefied wood, $80 \mathrm{~mL}$ 1,4-dioxane and $20 \mathrm{~mL}$ distilled water was titrated with 1 $\mathrm{mol} / \mathrm{L} \mathrm{NaOH}$ to the equivalence point $(\mathrm{pH} 8.3)$ using a $\mathrm{pH}$ meter to indicate the end-point by the following Eq. (1).

$$
\text { Acid value }(\mathrm{AV})=\frac{(A-B) N \times 56.1}{W}(\mathrm{mgKOH} / \mathrm{g})
$$

where,

A - the volume of $\mathrm{NaOH}$ standard solution consumed in sample titration $(\mathrm{ml})$

$\mathrm{B}$ - the volume of $\mathrm{NaOH}$ standard solution consumed in blank titration $(\mathrm{ml})$

$\mathrm{N}$ - the equivalent concentration of, $\mathrm{KOH}$ solution used

$\mathrm{W}$ - the weight of the biomass sample (g)

A mixture of $1.0 \mathrm{~g}$ of liquefied wood sample and $25 \mathrm{~mL}$ phthalation reagent was heated at $110^{\circ} \mathrm{C}$ for $20 \mathrm{~min}$. This was followed by the addition of $50 \mathrm{~mL}$ dioxane and $25 \mathrm{~mL}$ distilled water. The mixture was titrated with a $1.0 \mathrm{~mol} / \mathrm{L} \mathrm{NaOH}$ solution to the equivalence point using a $\mathrm{pH}$ meter. The phthalation reagent consisted of a mixture of $150 \mathrm{~g}$ phthalic anhydride, $24.2 \mathrm{~g}$ imidazole, and 1,000 g dioxane. Blank titration was conducted using the same procedure. Hydroxyl value in $\mathrm{mg} \mathrm{KOH} \mathrm{g}^{-1}$ of liquefied wood sample was calculated by the following Eq. (2).

$$
\text { Hydroxyl value }=\frac{(B-C) N \times 56.1}{W}+A V(\mathrm{mgKOH} / \mathrm{g})
$$


Here,

$\mathrm{C}$ : the volume of $\mathrm{NaOH}$ standard solution consumed in sample titration $(\mathrm{ml})$

\subsection{Synthesizing and measuring epoxy resin}

The route for the synthesis of wood-based epoxy resins was basically same as the general synthesis method for commercially available epoxy resins $[10,11]$.

Step 1: The liquefied wood and epichlorohydrin were put into a $500 \mathrm{~mL}$ three-necked glass flask. The amount of epichlorohydrin was set as 15 times of the molar ratio of hydroxyl value of liquefied wood sample. This means the epichlorohydrin was put in the reaction system excessively.

Step 2: Premixing, Tetrabutylammonium Hydrogen Sulfate (TBAHS) (aphasic transfer catalyst) and $\mathrm{NaOH}$ (the amount was 4.5 times of molar ratio compared to hydroxyl value of liquefied wood sample) were slowly added to the composition with stirring.

Step 3: The flask was kept at $60^{\circ} \mathrm{C}$ for $4 \mathrm{~h}$.

Step 4: The reacted products were diluted with acetone, and salts as by-products were filtered out with a filter paper made of glass-fiber (Toyo GA-100: $1 \mu \mathrm{m}$ particle-retainable).

Step 5: Epichlorohydrin in the filtered resin solution were evaporated using a rotary evaporator at $80^{\circ} \mathrm{C}$ under reduced pressure. Then, the wood-based epoxy resin remained in the flask of the evaporator.

Viscosity, thermal stability and thermal property were selected for the sake of comparing the original woody material (OM) and decayed woody material (DM) in line with Kishi et al. [10]. Differential scanning calorimetry (DSC) (DSC6200, Seiko Instruments Inc., Japan) were used under air condition. Argon gas was chosen as the incoming air of TG-DTA system (DTG-60, Shimazu Corporation, Japan) was to avoid combustion reaction. $5.0 \mathrm{mg}$ samples were weighed carefully and then encapsulated in open platina pans and heated in the presence of an empty crucible as reference. The heating rate was $10^{\circ} \mathrm{C} / \mathrm{min}$ from room temperature to $500^{\circ} \mathrm{C}$ under argon atmosphere. For each heating rate, it was recorded as heat flow versus temperature.

\section{RESULTS AND DISCUSSION}

\subsection{Acidity and hydroxyl values of liquefied wood}

The hydroxyl value of liquefied wood is one of the important factors in the preparation of epoxy resin. Table 2 shows the acidity and hydroxyl value of liquefaction. As can be seen, the acidity value of liquefied wood of DM $(9.2 \mathrm{mg}$ $\left.\mathrm{KOH} . \mathrm{g}^{-1}\right)$ is higher than that of OM (8.8 mg KOH.g-1) and the hydroxyl number of liquefied wood of DM (327 mg KOH.g $\left.{ }^{-1}\right)$ is lower than that of OM (690 mg KOH.g $\left.{ }^{-1}\right)$. According to Chen et al. [12]. added wheat straw played a role in decreasing the peak value of hydroxyl number through degradation reaction. Considering the data of residue as shown in Figure 2 [8], the result in this study is corresponded each other. In other words, the acidity value of samples increased and the hydroxyl number decreased when wood was decayed because decay can be pre-treatment of liquefaction. This study indicated that acidic substances can be produced by the thermal oxidation of carbohydrates and lignin during the liquefaction of lignocellulosic materials. Likewise, in this study the increase in acidity numbers also indicate the generation of acidic substances during liquefaction. The reduction of hydroxyl number was thought to be caused either by dehydration reactions between liquefied products and polyhydric alcohols or by thermal oxidation that may also occur during liquefaction.

Table 2. The results of acidity and hydroxyl values of the liquefied wood

PEG 400-glycerin mixture: 9/1, liquid ratio: 6/1, catalyst concentration: $10 \%$ and reaction time: $300 \mathrm{~min}$

\begin{tabular}{|c|c|c|}
\hline Material & $\begin{array}{c}\text { Acidity value } \\
(\mathrm{mgKOH} / \mathrm{g})\end{array}$ & $\begin{array}{c}\text { Hydroxyl value } \\
\text { (mgKOH/g) }\end{array}$ \\
\hline original woody material & 11.2 & 692.5 \\
\hline decayed woody sample & 9.2 & 527.3 \\
\hline
\end{tabular}

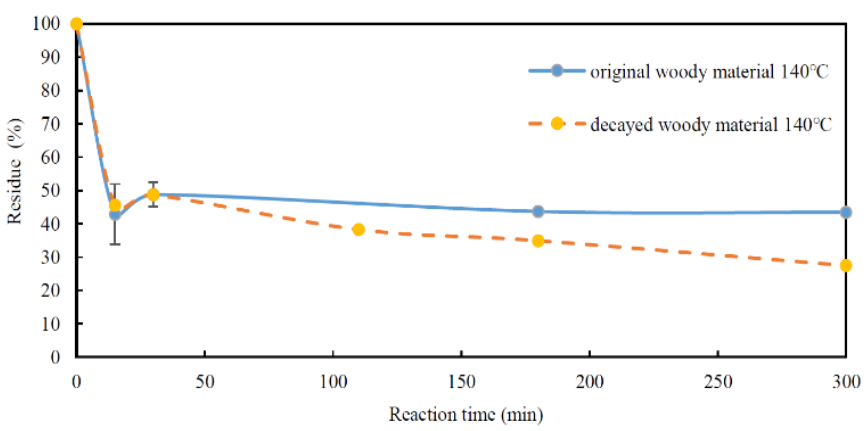

Figure 2. Reaction of the residue of liquefaction in the woody samples; comparison between decayed woody material from mushroom cultivation and original woody material at $140^{\circ} \mathrm{C}[8]$

\subsection{Synthesis of the liquefied wood-based epoxy resins}

The synthesis of wood-based epoxy resin is very similar to the general synthesis method for commercially available epoxy resin $[10,11]$. The mechanism of that is shown in the Figure 3. It is well known that the peak of $910 \mathrm{~cm}^{-1}$ in spectra shows vibration of the epoxy groups, which indicates the wood-based resin possesses epoxy functionality [13]. The liquefied wood-based epoxy resin was clipped thinly by potassium bromide plate and set the pellet in Fourriertransform infrared spectrosaopy (FTIR)(JASCO Co. Ltd., Japan), and we obtained both epoxy resin based on DM and OM have the peak of $910 \mathrm{~cm}^{-1}$ in spectra as illustrated in Figure 4. This may reveal even DM can be the resource of epoxy resin.

$$
\begin{aligned}
& \mathrm{R}-\mathrm{OH}+\mathrm{NaOH} \rightarrow \mathrm{R}-\mathrm{O}-\mathrm{Na}+\mathrm{H}_{2} \mathrm{O} \\
& \mathrm{R}-\mathrm{O}-\mathrm{Na}+\left(\mathrm{C}_{4} \mathrm{H}_{9}\right)_{4} \mathrm{~N}^{+} \mathrm{HSO}_{4}^{-} \rightarrow\left(\mathrm{C}_{4} \mathrm{H}_{9}\right)_{4} \mathrm{~N}^{+-}-\mathrm{O}^{-} \mathrm{R}^{-}+\mathrm{Na}^{+} \mathrm{HSO}_{4}^{-} \\
& \text {TBAHS } \\
& \left(\mathrm{C}_{4} \mathrm{H}_{9}\right)_{4} \mathrm{~N}^{+}-\mathrm{O}-\mathrm{R}^{-}+\mathrm{CH}_{2}-\mathrm{CH}-\mathrm{CH}_{2} \rightarrow\left(\mathrm{C}_{4} \mathrm{H}_{9}\right)_{4} \mathrm{~N}^{+} \mathrm{Cl}^{-}+\mathrm{R}-\mathrm{O}-\mathrm{CH}_{2}-\mathrm{CH}-\mathrm{CH}_{2} \\
& \mathrm{Cl} \mathrm{O}^{\prime}{ }^{\prime} \mathrm{O} \text { ' } \\
& \mathrm{Na}^{+} \mathrm{HSO}_{4}^{-}+\left(\mathrm{C}_{4} \mathrm{H}_{9}\right)_{4} \mathrm{~N}^{+} \mathrm{Cl}^{-} \rightarrow\left(\mathrm{C}_{4} \mathrm{H}_{9}\right)_{4} \mathrm{~N}^{+} \mathrm{HSO}_{4}^{-}+\mathrm{NaCl} \\
& \text { TBAHS }
\end{aligned}
$$

Figure 3. Reaction routes for glycidyl etherification (epoxidation) of alcoholic $\mathrm{OH}$ groups using $\mathrm{NaOH}$ and TBAHS 


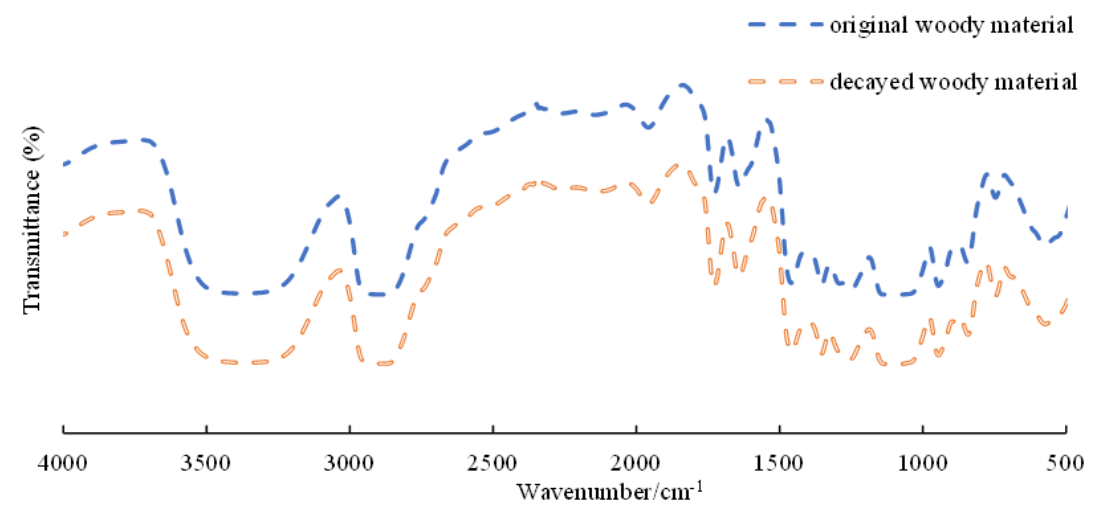

Figure 4. The FT-IR spectra of liquefied wood-based epoxy resins

\subsection{Viscosity of the liquefied woods and the liquefied wood- based epoxy resins}

Viscosity is one of the important indexes for determining the application of epoxy resin. Both liquefied woods and epoxy resins were dried in room temperature using desiccator to eliminate extra moisture. As shown in Figure 5, viscosity of Liquefed wood of DM and OD is almost the same. However, in regards to viscosity of epoxy resin, DW is barely higher than OD. Data presented in previous investigation [14] using various rate of wood material indicated that increased wood content resulted in markedly higher viscosity of liquefied woods. The reason is the increase in the amount of liquefied woods fragments having partially degraded wood components. It means DW is somewhat easy to decompose and more extent larger amount of liquefied woods fragments is dissolved. High viscosity epoxy resins exhibit traits such as temperature resistance; both low and high, good chemical resistance, and great adhesion to a variety of substrates such as plastics, wood, and composites. They are often used for castings or molds as well as in the manufacturing of water skis and snowboards [15]. So, the feature that epoxy resin made from DW is liquid in room temperature and have higher viscosity means that DW is superior for material of epoxy resin.

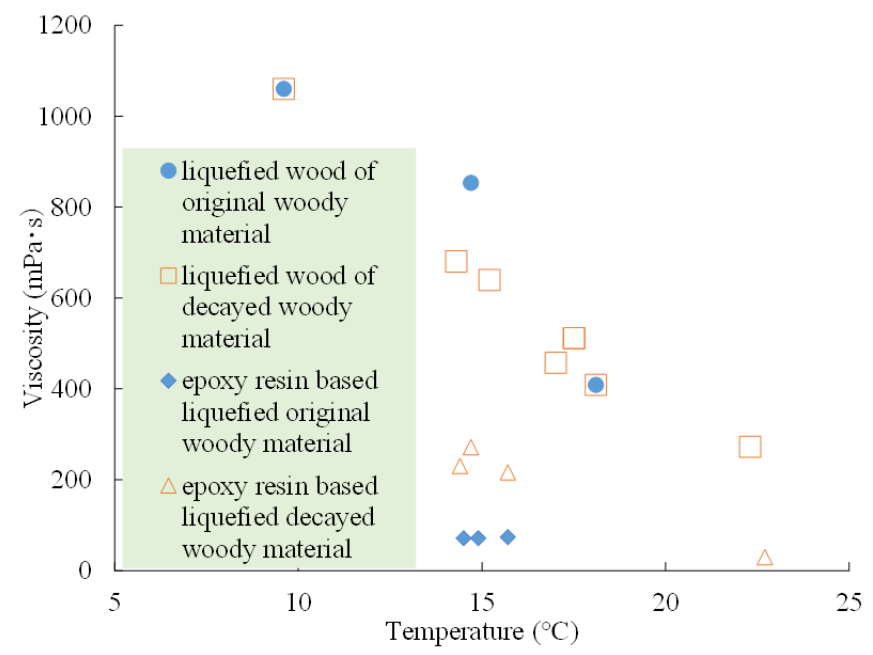

Figure 5. The results of viscosity of the liquefied wood and the liquefied wood-based epoxy resins

Epoxy resins have considerably lower viscosity than liquefied wood, which is came from used reagents such as epichlorohydrin in the manufacturing process.

\subsection{Thermal stability of the epoxy resins based on liquefied wood}

The consequence gained in previous studies [16] using a wood-based epoxy resin and the alcohol-based epoxy resin as reference cured with polyamide amine describe that the higher the glass transition temperatures $(\mathrm{Tg})$ of the wood-based epoxy resin than that of the alcohol-based epoxy resin. These dates suggested that the wood derived molecules were chemically incorporated into the network structures. In the present study, we evaluated thermal stability using differential scanning calorimetry (DSC) (DSC6200, Seiko Instruments Inc., Japan). Samples weighing up to $10 \mathrm{mg}$ were weighed carefully, encapsulated in open aluminum pans and heated in the presence of an empty crucible as reference. The heating rate of $10^{\circ} \mathrm{C} / \mathrm{min}$ from $25^{\circ} \mathrm{C}$ to $600^{\circ} \mathrm{C}$ under air environment. It was recorded heat flow versus temperature. Figure 6 shows the results of DSC curves of the liquefied wood-based epoxy resin. At temperatures lower than $100^{\circ} \mathrm{C}$, the small weight loss is attributed due to vaporization of the moisture attached to the surface of the samples. The weight loss was occurred nearly $135^{\circ} \mathrm{C}$. Because of DW consists of $78.0 \%$ holocellulose (cellulose and hemicellulose), and $22.7 \%$ lignin, the two peaks in the DSC curves were attributed to decomposition of hemicelluloses and cellulose, respectively. In contrast, control is made up of $80.0 \%$ holocellulose (cellulose and hemicellulose), and $21.0 \%$ lignin. Therefore, the peaks between $220-350^{\circ} \mathrm{C}$ in the DSC curves are mostly due to the decomposition of hemicellulose. This result is in good agreement with literature data [16-18], which states that hemicellulose decomposes between 220 and $315^{\circ} \mathrm{C}$ while cellulose decomposes between 315 and $400^{\circ} \mathrm{C}$.

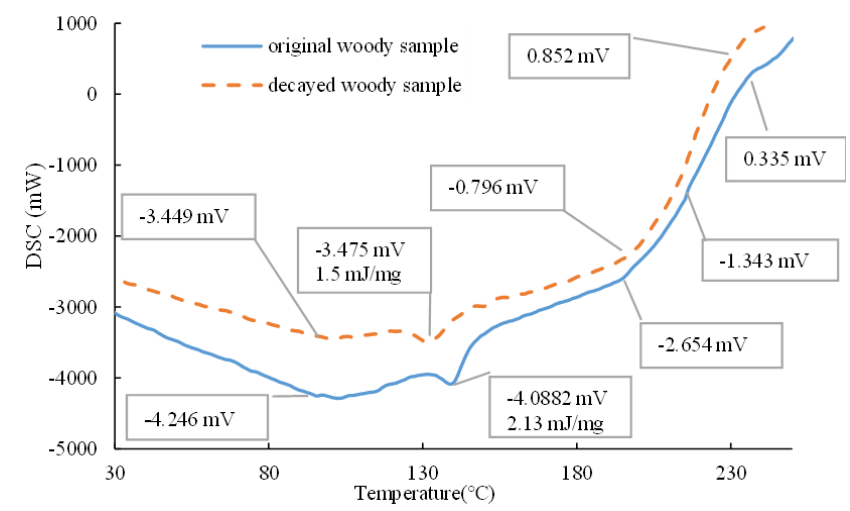

Figure 6. The results of DSC of the liquefied wood-based epoxy resins 


\subsection{Thermal properties of the epoxy resin based on liquefied wood}

Epoxy resin is one of the most important functional polymers that are being used in various applications, but the poor thermal properties limit its applications. There are many studies $[11,19]$ to enhance the thermal properties of epoxy resin. Fujiwara et al. [11] synthesized epoxy resins containing various amount of woody sample and material decreased as the increase of the amount of the woody sample. They suggested that the reason is the high amount of the content based on wood, which is easy to thermal decomposition. The wood mainly contains cellulose, hemicellulose and lignin have the wide range of thermal decomposition $\left(160-450^{\circ} \mathrm{C}\right)$ [20]. In this study, we evaluated the thermal properties by TG-DTA system (DTG-60, Shimazu Corporation, Japan). The thermogravimetric curves of the liquefied wood-based epoxy resin are shown in Figure 7 and Figure 8. DW is found to decompose at about $230^{\circ} \mathrm{C}$ and lost 80.7 wt. \% of its initial weight at $30^{\circ} \mathrm{C}$. The highest degradation temperature of the DW is found to be as $230^{\circ} \mathrm{C}$. On the other hand, the $\mathrm{OW}$ is found to decompose at about $150^{\circ} \mathrm{C}$ and lost $89.5 \mathrm{wt}$. \% of its initial weight at $30^{\circ} \mathrm{C}$. The temperature at which $\mathrm{OW}$ presented the highest decomposition rate is about $297^{\circ} \mathrm{C}$. Both of decomposition appears at about $250^{\circ} \mathrm{C}$ and can be attributed to the decomposition of pyranose rings. There is no difference on the rate of decrease of weight, but the initial temperature of DW is lower than OW. DW has relatively higher ratio of the content base on wood which is depending on less amount of regent such as epichlorohydrin, the thermal decomposition of that tends to decrease.

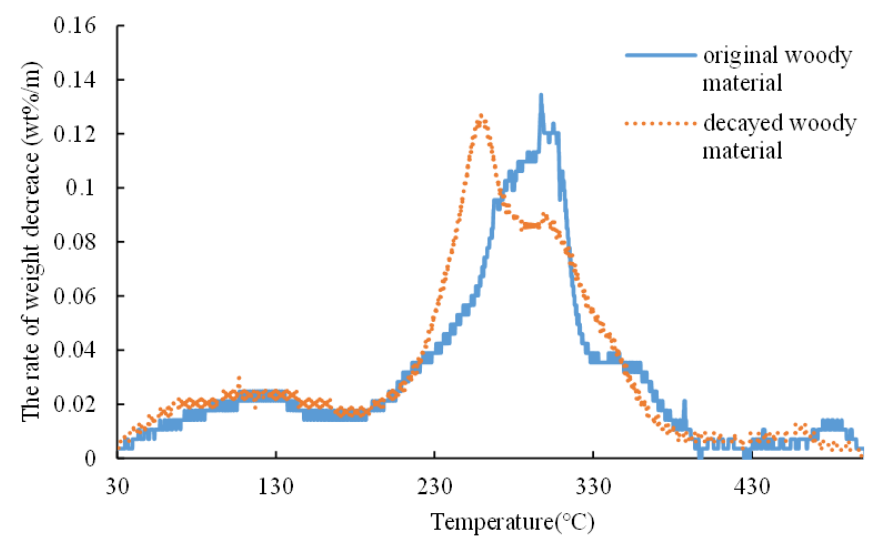

Figure 7. Thermogravimetric curves of the liquefied woodbased epoxy resins

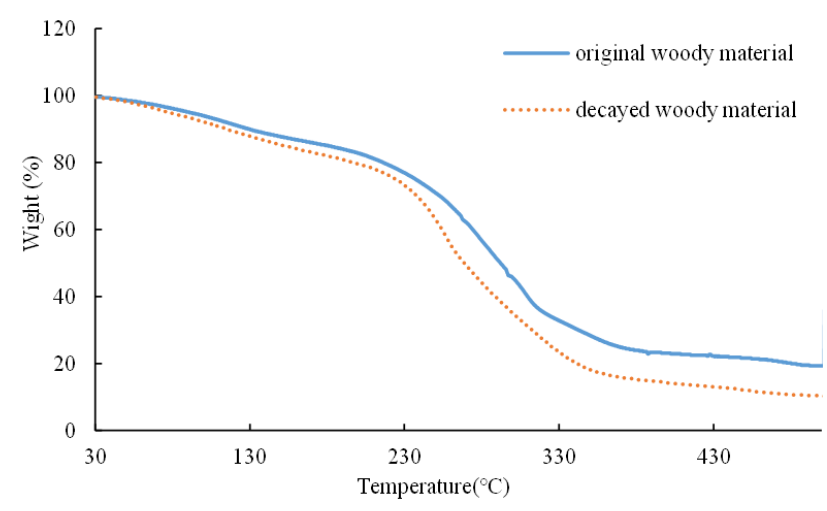

Figure 8. Rate of weight decrease of the liquefied woodbased epoxy resins

\section{CONCLUSION}

Epoxy resin has good mechanical and adhesive performance, and is widely used in various fields such as adhesives, coatings and matrix resins of composites. However, only very few studies have addressed decayed wood. The purpose of this study is to synthesize and analyze liquefied wood and the epoxy resin made from it. In this study, we synthesized epoxy resin from the liquefied wood after cultivated mushroom and compare with the original woody material for chemical and mechanical property. We found epoxy resin made from decayed woody has almost the same viscosity, IR spectra thermal stability and thermal decomposition with original woody materials, which means even decayed wood can be regarded as material for liquefaction. The ratio of the content based on wood and the thermal decomposition of liquefied wood sample of liquefied wood of decayed wood is a little higher than that of original woody material, which is proved by the high hydroxyl number. To the knowledge of the authors, this is the first study to investigate the effect of decay on resin made from liquefied wood. These finding extended the potential of liquefaction technology. In addition, the valid information noted in our study can contributes to solve the forestry waste and reduce the environmental problem. Our results have proved that epoxy resin prepared from decayed woody material can be used for many applications such as binding. However, some limitations are necessary to be mentioned. Although our hypotheses were supported, the used sample was the specific cherry biomass tree and epoxy resin was not cured yet. Therefore, future work should include various types of tree and nonwood material cured material for analysis of property.

\section{ACKNOWLEDGMENT}

Some works of this study were supported by the Special Funds for Grant-in-Aid for Scientific Research (B) (No. 15H05119, FY2015 2017, No.18H03384, FY2018 2020) of Japan Society for the Promotion of Science (JSPS) and Japanese Ministry of Education, Culture, Sports, Science and Technology (MEXT), Japan.

\section{REFERENCES}

[1] Pu, S., Shiraishi, N. (1993). Liquefaction of wood without a catalyst II. Weight loss by gasification during wood liquefaction, and effects of temperature and water. MokuzaiGakkaishi, 39(4): 446-458.

[2] Yamada, T., Ono, H. (2001). Characterization of the products resulting from ethylene glycol liquefaction of cellulose. The Japan Wood Research Society, 47: 458464. https://doi.org/10.1007/BF00767898

[3] Kurimoto, Y., Takeda, M., Koizumi, A., Yamauchi, S., Doi, S., Tamura, Y. (2000). Mechanical properties of polyurethane films prepared from liquefied wood with polymeric MDI. Bioresource Technology, 74(2): 151157. https://doi.org/10.1016/S0960-8524(00)00009-2

[4] Lu, Y.S., Tighzert, L., Dole, P., Erre, D. (2005). Preparation and properties of starch thermoplastics modified with waterborne polyurethane from renewable resources. Polymer, 46(23): 9863-9870. https://doi.org/10.1016/j.polymer.2005.08.026 
[5] Feldman, D., Banu, D., Natansohn, A., Wang, A. (1991). Structure-properties relations of thermally cured epoxylignin polyblends. Journal of Applied Polymer Science, 42(6):

$1537-1550$ https://doi.org/10.1002/app.1991.070420607

[6] Xie, T., Chen, F. (2005). Fast liquefaction of bagasse in ethylene carbonate and preparation of epoxy resin from the liquefied product. Journal of Applied Polymer Science, 25(4): 86-90.

[7] Wang, Q., Takahashi, H., Kawamura S., Hatakeyama, S. (2017). Basic study on decayed behavior of waste samples woody samples caused by three white-rot fungi. WIT Transactions on Ecology and the Environment, 224: 267-277. https://doi.org/10.2495/ESUS170251

[8] Wang, S., Kawamura, S. (2018). Decayed woody material from mushroom cultivation: characterization of liquefaction. WIT Transactions on Ecology and the Environment, 217: 481-492. https://doi.org/10.2495/SDP180431

[9] Ertaş, M., Fidan, M.S., Alma, M.H. (2014). Preparation and characterization of biodegradable rigid polyurethane foams from the liquefied eucalyptus and pine woods. Wood Res Slovak, 59(1): 97-108.

[10] Kishi, H., Fujita, A. (2008). Wood-based epoxy resins and the ramie fiber reinforced composites. Environmental Engineering and Management Journal, 7(5): 517-523.

[11] Fujiwara, T., Noguchi, M., Akamatsu, Y., Nishida, H., Matsuda, S., Kishi, H. (2012). The alcohol-liquefied wood-based epoxy resins - relation between the woodliquefied solvent type and the mechanical properties. Journal of Network Polymer, Japan, 33(1): 26-33.

[12] Chen, F., Lu, Z. (2009). Liquefaction of Wheat straw and preparation of rigid polyurethane foam from the liquefaction products. Journal of Applied Polymer Science, 111(1): 508-516 https://doi.org/10.1002/app.29107
[13] Zambrzycki, M., Fraczek-Szczypta, A. (2018). Conductive hybrid polymer composites based on recycled carbon fibers and carbon nano fillers. J. Mater Sci., 53: 7403-741. https://doi.org/10.1007/s10853-0182062-5

[14] Kishi, H., Akamatsu, Y., Noguchi, M., Fujita, A., Matsuda, S., Nishida, H. (2011). Synthesis of epoxy resins from alcohol-liquefied wood and the mechanical properties of the cured resins. J. Appl. Polym. Sci., 120(2): 745-751. https://doi.org/10.1002/app.33199

[15] Kurimoto, Y., Takeda, M., Koizumi, A., Yamauchi, S., Doi, S., Tamura, Y. (2000). Mechanical properties of polyurethane films prepared from liquefied wood with polymeric MDI. Bioresource Technology, 74(2): 151157. https://doi.org/10.1016/S0960-8524(00)00009-2

[16] Yang, H., Yan, R., Chen, H., Zheng, C., Lee, D.H., Liang, D.T. (2006). In-depth investigation of biomass pyrolysis based on three major components: hemicellulose, cellulose and lignin. Energy \& Fuels, 20(1): 388-393. https://doi.org/10.1021/ef0580117

[17] Muller-Hagedorn, M., Bockhorn, H., Krebs, L., Muller, U. (2003). A comparative kinetic study on the pyrolysis of three different wood species. J. Anal. Appl. Pyrol, 6869: 231-249. https://doi.org/10.1016/S01652370(03)00065-2

[18] Wang, G., Li, W., Li, B., Chen, H. (2008). TG study on pyrolysis of biomass and its three components under syngas. $\quad$ Fuel, $87(4-5)$ : $552-558$. https://doi.org/10.1016/j.fuel.2007.02.032

[19] Wu, C.C., Lee, W.J. (2010). Curing and thermal properties of copolymer epoxy resins prepared by copolymerized bisphenol-A and epichlorohydrin with liquefied Dendrocalamuslatiflorus. Polymer Journal, 42: 711-715. https://doi.org/10.1038/pj.2010.64

[20] Yamashita, N., Machida, M., Aikawa, M., Tatsumoto, H. (2009). Preparation of porous bamboo carbon by lowtemperature activation in air. MokuzaiGakkaishi, 55(5): 299-304. https://doi.org/10.2488/jwrs.55.299 